\title{
Connexin expression and gap-junctional intercellular communication in ES cells and iPS cells
}

\author{
Masahito Oyamada ${ }^{1 *}$, Kumiko Takebe ${ }^{1}$, Aya Endo ${ }^{1}$, Sachiko Hara ${ }^{1}$ and Yumiko Oyamada ${ }^{2}$ \\ ${ }^{1}$ Department of Food Science and Human Nutrition, Faculty of Human Life Sciences, Fuji Women's University, Ishikarishi, Japan \\ ${ }^{2}$ Department of Surgical Pathology, Tonan Hospital, Sapporo, Japan
}

\author{
Edited by: \\ Stefan Dhein, Herzzentrum Leipzig \\ GmbH - Universitätsklinik, Germany \\ Reviewed by: \\ Olga Zegarra-Moran, Istituto \\ Giannina Gaslini, Italy \\ Marc Chanson, University of \\ Geneva, Switzerland \\ *Correspondence: \\ Masahito Oyamada, Department of \\ Food Science and Human Nutrition, \\ Faculty of Human Life Sciences, Fuji \\ Women's University, Hanakawa \\ Minami 4-jou 5-choume, Ishikarishi, \\ Hokkaido 061-3204, Japan \\ e-mail: oyamada@fujijoshi.ac.jp
}

Pluripotent stem cells, i.e., embryonic stem (ES) and induced pluripotent stem (iPS) cells, can indefinitely proliferate without commitment and differentiate into all cell lineages. ES cells are derived from the inner cell mass of the preimplantation blastocyst, whereas iPS cells are generated from somatic cells by overexpression of a few transcription factors. Many studies have demonstrated that mouse and human iPS cells are highly similar but not identical to their respective ES cell counterparts. The potential to generate basically any differentiated cell types from these cells offers the possibility to establish new models of mammalian development and to create new sources of cells for regenerative medicine. ES cells and iPS cells also provide useful models to study connexin expression and gap-junctional intercellular communication (GJIC) during cell differentiation and reprogramming. In 1996, we reported connexin expression and GJIC in mouse ES cells. Because a substantial number of papers on these subjects have been published since our report, this Mini Review summarizes currently available data on connexin expression and GJIC in ES cells and iPS cells during undifferentiated state, differentiation, and reprogramming.

Keywords: connexins, gap-junctional intercellular communication, ES cells, iPS cells, differentiation, reprogramming, pluripotency

\section{INTRODUCTION}

Gap junctions are cell-cell communicating junctions that consist of multimeric proteins called connexins and mediate the exchange of low-molecular-weight metabolites and ions between contacting cells (Oyamada et al., 2013). Gap-junctional intercellular communication (GJIC) has long been hypothesized to play a crucial role in the maintenance of homeostasis, morphogenesis, cell differentiation, and growth control in multicellular organisms. Discoveries of human genetic disorders due to mutations in connexin genes and experimental data on connexin knockout mice provide direct evidence that gap junctional intercellular communication is essential for tissue functions and organ development and that its dysfunction causes diseases. Connexinrelated signaling also involves extracellular signaling (hemichannels) and non-channel intracellular signaling.

GJIC during embryonal development has been demonstrated by using microelectrode impalements to monitor the cell-tocell movement of ions (ionic coupling) and by microinjection of small-molecular-weight fluorescent dyes such as Lucifer yellow into a single cell and observation of the subsequent dye spread into the surrounding cells (dye coupling) (Lo and Gilula, 1979; Kalimi and Lo, 1988, 1989). It has been revealed that in many instances, GJIC is established within the first few cleavages and results in the entire embryo becoming interconnected as a syncytium. As development progresses, however, dye coupling delineates boundaries defining restrictions in GJIC that effectively segregate the developing embryo or tissue into a number of "communication compartment" domains. Thus, cells lying within a communication compartment are well coupled, exhibiting both ionic and dye coupling, whereas there is little or no coupling between cells situated across a compartment border. Such restriction of GJIC and the segregation of cells into communication compartment domains are almost always associated with embryogenesis and development.

Pluripotent stem cells, which include embryonic stem (ES) cells and induced pluripotent stem (iPS) cells, possess the ability to proliferate indefinitely without commitment in vitro and also differentiate into all cell lineages belonging to the three embryonic germ layers (Evans and Kaufman, 1981; Thomson et al., 1998; Takahashi and Yamanaka, 2006; Takahashi et al., 2007). ES cells are derived from the inner cell mass of the preimplantation blastocyst, whereas iPS cells are generated from many different types of somatic cells by overexpression of only a few pluripontency-related transcription factors. Many studies have demonstrated that mouse and human iPS cells are highly similar but not identical to their respective ES cell counterparts morphologically, functionally, and molecularly at the level of transcription and genome-wide distribution of chromatin modification. The potential to generate basically any differentiated cell types from ES cells and iPS cells offers the possibility to establish new models of mammalian development and to create new sources of cells for regenerative medicine (Robinton and Daley, 2012).

The in vitro differentiation system using ES cells and iPS cells also provides a useful model to study connexin expression and GJIC during the early stage of cell differentiation (Wong et al., 
2008; Sharovskaya, 2011). In addition, the importance of understanding the regulation of connexin expression in differentiating pluripotent cells is recognized in regenerative medicine.

In 1996, we first reported the expression of connexin genes and GJIC during in vitro cardiomyocyte differentiation of mouse ES cells (Oyamada et al., 1996). Because a substantial number of papers on these subjects have been published since our first report, this Mini Review summarizes currently available data on connexin expression and GJIC in ES cells and iPS cells during undifferentiated state, differentiation, and reprogramming.

\section{QUESTIONS ABOUT CONNEXIN EXPRESSION AND GAP-JUNCTIONAL INTERCELLULAR COMMUNICATION IN ES/IPS CELLS}

Main questions about connexin expression and GJIC in ES/iPS cells that have been addressed thus far can be summarized as below:

1. What kinds of connexins are expressed in undifferentiated ES/iPS cells?

2. To what extent do undifferentiated ES/iPS cells communicate with each other via gap junctions?

3. What changes in connexin expression and GJIC occur during differentiation of ES/iPS cells?

4. What roles do connexin expression and/or GJIC play in maintenance of pluripotency in ES/iPS cells?

5. What changes in connexin expression and GJIC occur during induction of pluripotency in somatic cells (reprogramming)?

6. What roles do connexin expression and/or GJIC play in reprogramming?

\section{CURRENTLY AVAILABLE DATA ON CONNEXIN EXPRESSION AND GAP-JUNCTIONAL COMMUNICATION IN ES CELLS}

Table 1 summarizes results of published papers concerning connexin expression and GJIC in ES cells.

\section{CONNEXIN EXPRESSION AND GAP-JUNCTIONAL INTERCELLULAR COMMUNICATION IN IPS CELLS}

Table 2 summarizes results of published papers concerning connexin expression and GJIC in iPS cells.

Using human iPS cells, Sharovskaya et al. (2012) reported that GJIC is re-established during reprogramming to pluripotency: GJIC in incompletely reprogrammed cells was markedly decreased compared with that in the parental somatic cells, but GJIC in completely reprogrammed cells exceeded that in the parental somatic cells and was comparable to that in human ES cells. They drew an analogy between dramatic reduction of GJIC among the cells undergoing early reprogramming and weak GJIC or lack thereof among epithelial stem cells, such as keratinocyte stem cells, breast epithelial, and neural-glial stem cells, suggesting that changes in GJIC during early reprogramming might be associated with mesenchymal-to-epithelial transition (MET). They also showed that the opposite process of cell differentiation from the pluripotent state leads to the disruption of GJIC between pluripotent and differentiated cell subsets. However, GJIC is subsequently re-established de novo within each differentiated cell type in vitro, forming communication compartments within a histotype. Human iPS cells they utilized were derived from human umbilical vein endothelial cells (HUVECs) by lentiviral transfection with four transcription factors: KLF4, OCT4, SOX2, and C-MYC. To evaluate changes in GJIC during late stages of reprogramming, incompletely reprogrammed endo-iPSC10 cells at passage 6 and completely reprogrammed cells of the same line at passage 26 were studied. Incompletely reprogrammed iPS cells were characterized by residual expression of endothelial-specific genes including Cx37 and reduced expression of pluripotencyrelated genes. In addition, they compared expression of connexins in HUVEC, endo-iPS-10, 12, and human ES cells and found that only Cx37 and Cx43 expression varied significantly in the examined cell types. In incompletely reprogrammed iPS cells, Cx37 and Cx43 were expressed at the level similar to HUVEC. In faithfully reprogrammed iPS cells, cells lacked characteristics of parental HUVEC Cx37 expression, whereas Cx43 expression increased three- to five-fold.

Ke et al. (2013) demonstrated that Cx43 is specifically and highly enriched in undifferentiated human iPS cell lines during and after the reprogramming process. They also showed that iPS cells display functional GJIC and that $\mathrm{Cx} 43$ expression is gradually upregulated $(\sim 4.5$-fold increase) during the reprogramming process. They observed that the $\mathrm{Cx} 43$ protein level increased gradually along with the expression of the pluripotency marker NANOG. Because Cx43 has been identified as a downstream target of the key pluripotency transcription factors OCT4, SOX2 and NANOG (Boyer et al., 2005), Cx43 expression might be upregulated by the key factors during reprogramming. They also found that the ectopic expression of $\mathrm{Cx} 43$ enhances the reprogramming efficiency ( $\sim 3$-fold increase), whereas the knockdown of endogenous $\mathrm{Cx} 43$ expression by RNAi reduces the efficiency, possibly by affecting the MET process, as reported by changes in E-cadherin expression. In addition, they showed that pharmacological GJIC inhibitors, CBX, 18-a-GA and the Cx43 mimetic peptide GAP27, did not affect the efficiency of iPS cell generation, suggesting that the effect of $\mathrm{Cx} 43$ on the efficiency of iPS cell generation may be attributed to the $\mathrm{Cx} 43$ protein itself but not to the function of GJIC, i.e., through a GJIC-independent pathway.

Taken together, these results suggest that $\mathrm{Cx} 43$ may represent a pluripotency marker of iPS cells and may play an important role in the reprogramming process.

Lundy et al. (2013) recently have developed a cell culture protocol capable of generating and maintaining highly purified human ES cell- and iPS cell-derived cardiomyocytes for several months in vitro. They have shown that these human ES celland iPS cell-derived cardiomyocytes are capable of maturing to a phenotype that more closely resembles adult cardiomyocytes in both structure and function. A robust induction of key cardiac structural markers including $\mathrm{Cx} 43$ has been demonstrated in late-stage ES cell- and iPS cell-derived cardiomyocytes. These findings suggest that ES cell- and iPS cell-derived cardiomyocytes are capable of slowly maturing to more closely resemble the phenotype of adult cardiomyocytes and may eventually possess the potential to regenerate the lost myocardium with robust de novo force-producing tissue. 


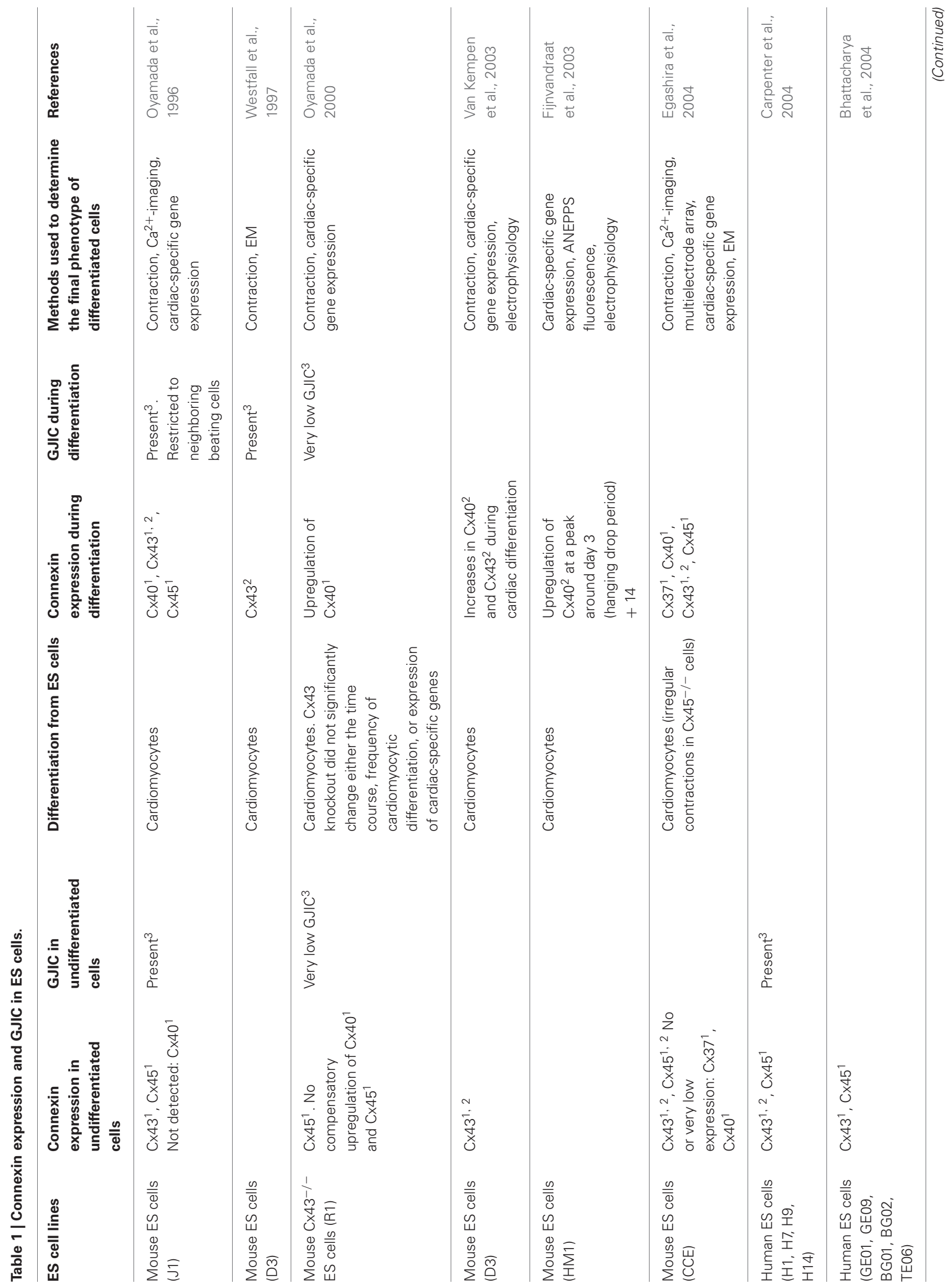




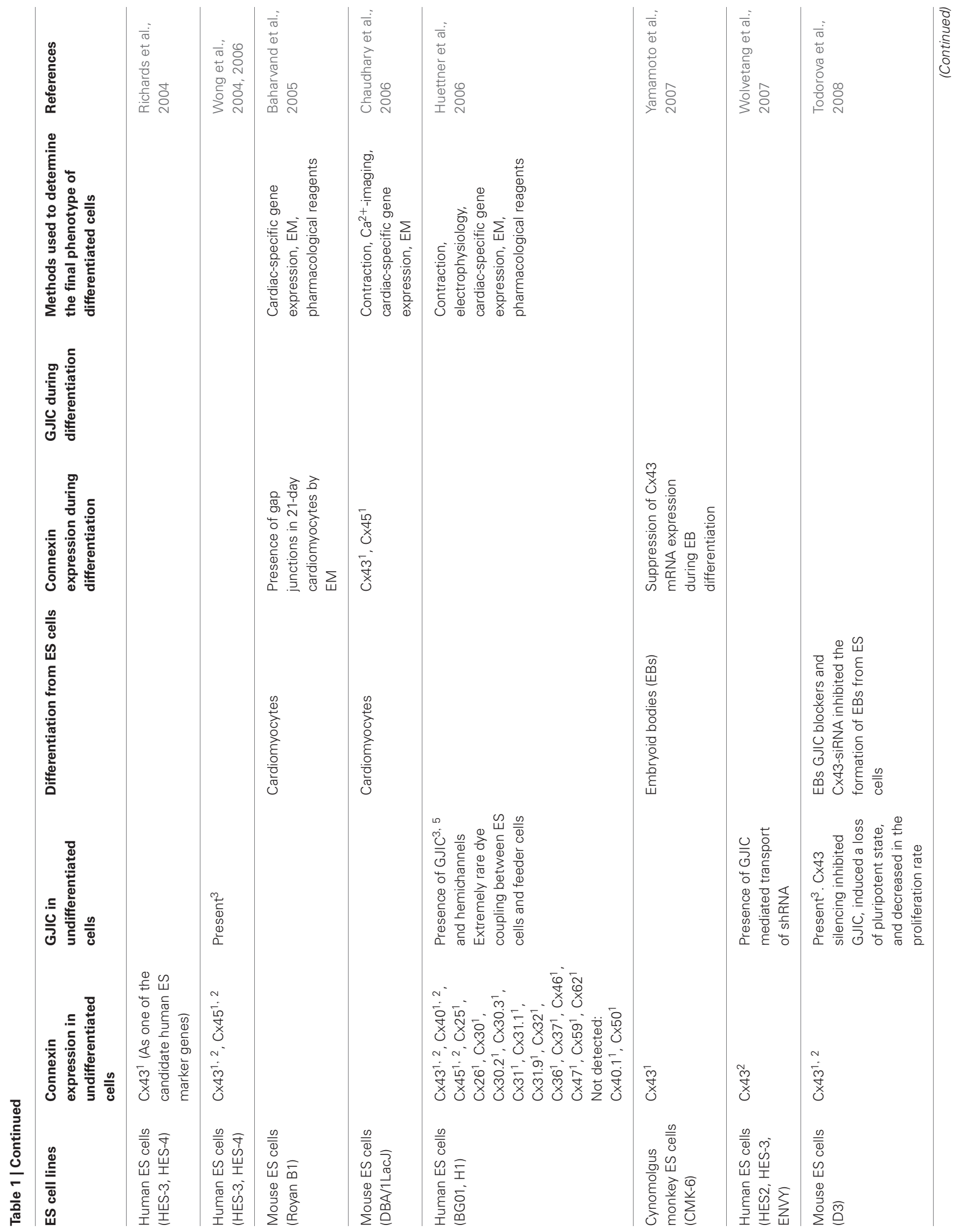




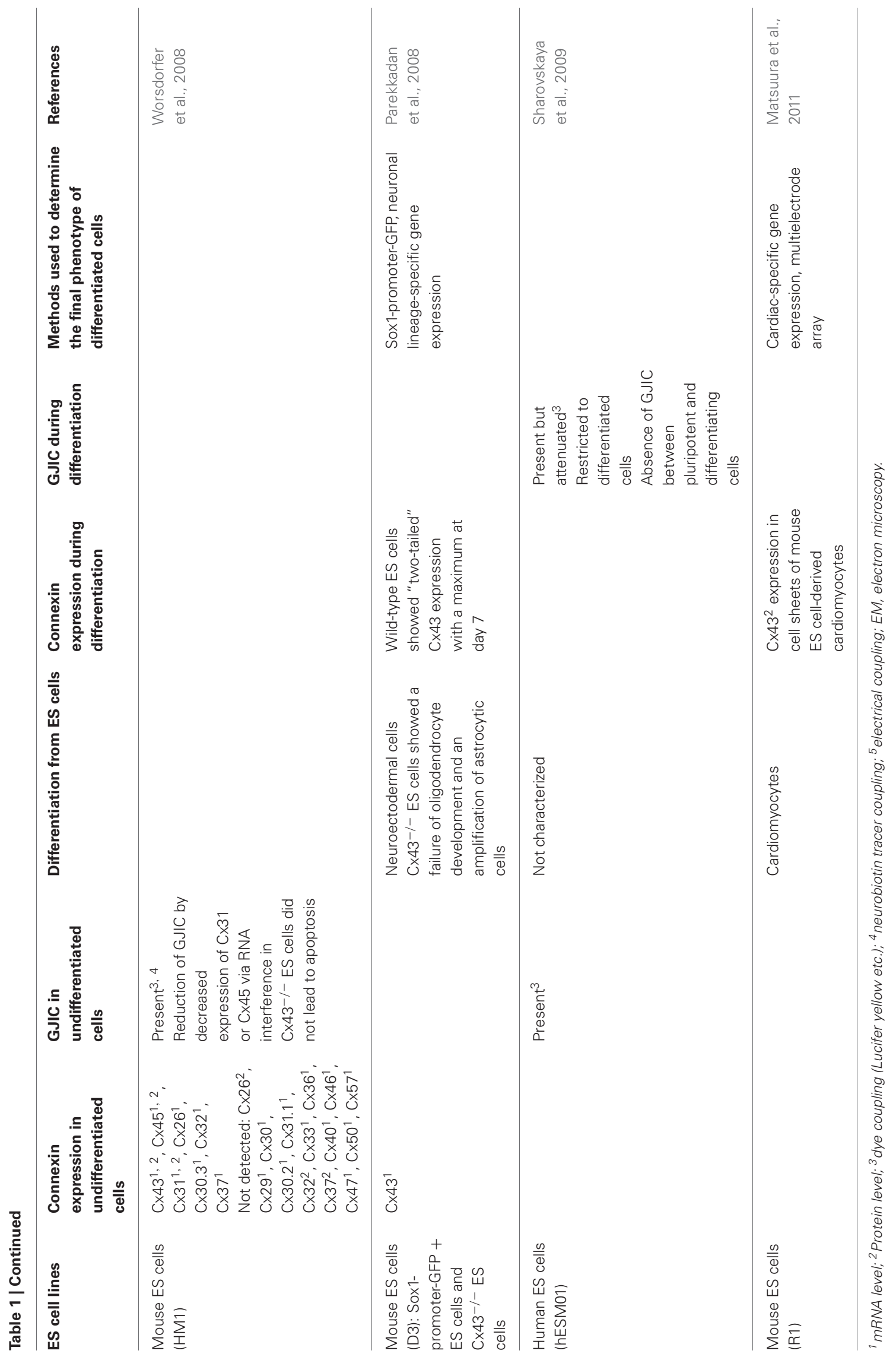




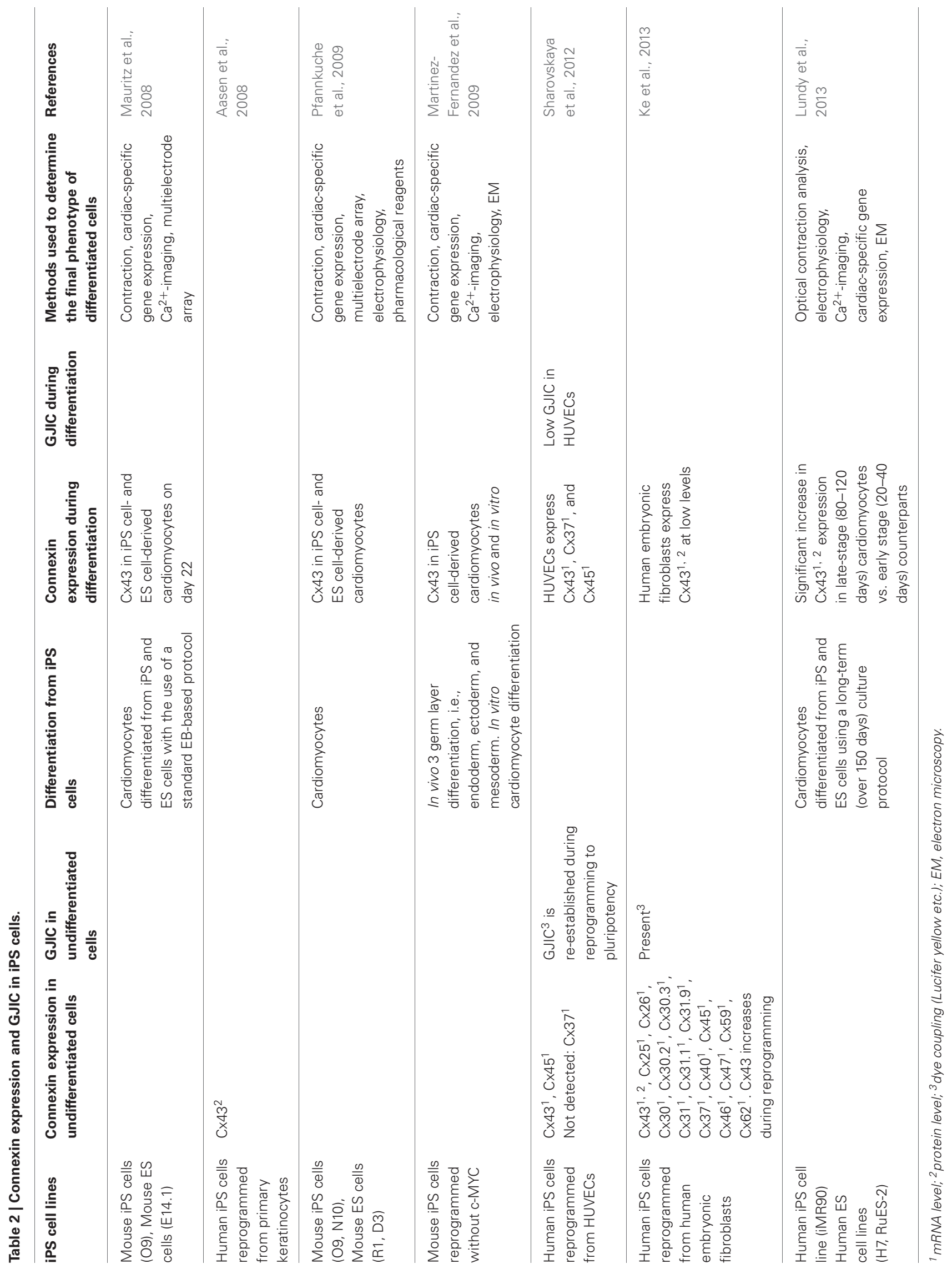




\section{CONCLUSIONS: CURRENT ANSWERS TO THE QUESTIONS ON CONNEXIN EXPRESSION AND GAP-JUNCTIONAL INTERCELLULAR COMMUNICATION IN ES/IPS CELLS}

It seems reasonable to conclude that mRNAs encoding almost all of the connexins are expressed in ES/iPS cells. At protein level, however, expression of only a few connexins, such as $\mathrm{Cx} 43, \mathrm{Cx} 45, \mathrm{Cx} 31$, and $\mathrm{Cx} 40$, has been confirmed. Many studies have shown that undifferentiated ES/iPS cells communicate with each other via gap junctions at a high level. Several studies using $\mathrm{Cx} 43$ RNAi demonstrated that $\mathrm{Cx} 43$ contributes substantially to a high level of GJIC in undifferentiated ES/iPS cells.

Concerning changes in connexin expression and GJIC during differentiation of ES/iPS cells, it has been shown that expression of tissue-related connexins, such as $\mathrm{Cx} 40, \mathrm{Cx} 43$, $\mathrm{Cx} 45$, and $\mathrm{Cx} 37$ in the cardiomyocyte, is upregulated and that GJIC between pluripotent and differentiated cells is disrupted, resulting in formation of "communication compartments." Regarding changes in connexin expression and GJIC during induction of pluripotency in somatic cells, the studies mentioned here have demonstrated that GJIC is re-established and $\mathrm{Cx} 43$ expression is upregulated during reprogramming to pluripotency.

\section{REFERENCES}

Aasen, T., Raya, A., Barrero, M. J., Garreta, E., Consiglio, A., Gonzalez, F., et al. (2008). Efficient and rapid generation of induced pluripotent stem cells from human keratinocytes. Nat. Biotechnol. 26, 1276-1284. doi: 10.1038/nbt.1503

Baharvand, H., Azarnia, M., Parivar, K., and Ashtiani, S. K. (2005). The effect of extracellular matrix on embryonic stem cellderived cardiomyocytes. J. Mol. Cell. Cardiol. 38, 495-503. doi: 10.1016/j.yjmcc.2004.12.011

Bhattacharya, B., Miura, T., Brandenberger, R., Mejido, J., Luo, Y., Yang, A. X., et al. (2004). Gene expression in human embryonic stem cell lines: unique molecular signature. Blood 103, 2956-2964. doi: 10.1182/blood2003-09-3314

Boyer, L. A., Lee, T. I., Cole, M. F., Johnstone, S. E., Levine, S. S., Zucker, J. P., et al. (2005). Core transcriptional regulatory circuitry in human embryonic stem cells. Cell 122, 947-956. doi: 10.1016/j. cell.2005.08.020

Carpenter, M. K., Rosler, E. S., Fisk, G. J., Brandenberger, R., Ares, X., Miura, T., et al. (2004). Properties of four human embryonic stem cell lines maintained in a feeder-free culture system. Dev. Dyn. 229, 243-258. doi: 10.1002/ dvdy.10431
Chaudhary, K. W., Barrezueta, N. X., Bauchmann, M. B., Milici, A. J., Beckius, G., Stedman, D. B., et al. (2006). Embryonic stem cells in predictive cardiotoxicity: laser capture ment. Toxicol. Sci. 90, 149-158. doi: 10.1093/toxsci/kfj078

Egashira, K., Nishii, K., Nakamura, K., Kumai, M., Morimoto, S., and Shibata, Y. (2004). Conduction abnormality in gap junction protein connexin45-deficient embryonic stem cell-derived cardiac myocytes. Anat. Rec. A Discov. Mol. Cell Evol. Biol. 280, 973-979. doi: 10.1002/ar.a.20110

Evans, M. J., and Kaufman, M. H. (1981). Establishment in culture of pluripotential cells from mouse embryos. Nature 292, 154-156. doi: 10.1038/292154a0

Fijnvandraat, A. C., Van Ginneken, A. C., Schumacher, C. A., Boheler, K. R., Lekanne Deprez, R. H., Christoffels, V. M., et al. (2003). Cardiomyocytes purified from differentiated embryonic stem chamber myocardium. J. Mol. Cell. Cardiol. 35, 1461-1472. doi: 10.1016/j.yjmcc.2003.09.011

Huettner, J. E., Lu, A., Qu, Y., Wu, Y., Kim, M., and McDonald, J. W. (2006). Gap junctions and connexon hemichannels in human embryonic stem cells. Stem Cells 24, 1654-1667. doi: 10.1634/stemcells.2005-0003 microscopy enables assay developcells exhibit characteristics of early

Cx43-mediated GJIC has been shown to play an important role in maintenance of pluripotency. In fact, pharmacological blockers of GJIC and Cx43 downregulation by siRNA have been shown to induce a loss of their pluripotent state in mouse ES cells (Todorova et al., 2008). Cx43 has also been shown to play an important role in reprogramming, possibly by GJIC-independent mechanism including effects on the MET process (Sharovskaya et al., 2012; Ke et al., 2013).

Because the literature on connexin expression and GJIC in iPS cells is limited, it is difficult to conclude whether there are differences between ES and iPS cells at present. However, available data suggest that human ES and iPS cells share a similar feature concerning expression and function of connexins.

Although important roles of connexin expression and/or GJIC in ES/iPS cells can be currently perceived, many critical questions including precise mechanisms by which connexin expression influences pluripotency and reprogramming remain to be clarified.

\section{ACKNOWLEDGMENTS}

This work was supported by grants-in-aid for Scientific Research from the Ministry of Education, Culture, Sports, Science, and Technology, Japan.

Kalimi, G. H., and Lo, C. W. (1988). Communication compartments in the gastrulating mouse embryo. J. Cell Biol. 107, 241-255. doi: 10.1083/jcb.107.1.241

Kalimi, G. H., and Lo, C. W. (1989). Gap junctional communication in the extraembryonic tissues of the gastrulating mouse embryo. J. Cell Biol. 109, 3015-3026. doi: 10.1083/jcb.109.6.3015

Ke, Q., Li, L., Cai, B., Liu, C. Yang, Y., Gao, Y., et al. (2013). Connexin 43 is involved in the generation of human-induced pluripotent stem cells. Hum. Mol. Genet. 22, 2221-2233. doi: 10.1093/hmg/ ddt074

Lo, C. W., and Gilula, N. B. (1979). Gap junctional communication in the preimplantation mouse embryo. Cell 18, 399-409. doi: 10.1016/00928674(79)90059-X

Lundy, S. D., Zhu, W. Z., Regnier, M., and Laflamme, M. A. (2013). Structural and functional maturation of cardiomyocytes derived from human pluripotent stem cells. Stem Cells Dev. doi: 10.1089/ scd.2012.0490. [Epub ahead of print].

Martinez-Fernandez, A., Nelson, T. J., Yamada, S., Reyes, S., Alekseev, A. E., Perez-Terzic, C., et al. (2009). iPS programmed without c-MYC yield proficient cardiogenesis for functional heart chimerism. Circ. Res. 105, 648-656. doi: 10.1161/CIRCRESAHA.109.203109
Matsuura, K., Masuda, S., Haraguchi, Y., Yasuda, N., Shimizu, T., Hagiwara, N., et al. (2011). Creation of mouse embryonic stem cell-derived cardiac cell sheets. Biomaterials 32, 7355-7362. doi: 10.1016/j.bio materials.2011.05.042

Mauritz, C., Schwanke, K., Reppel, M., Neef, S., Katsirntaki, K., Maier, L. S., et al. (2008). Generation of functional murine cardiac myocytes from induced pluripotent stem cells. Circulation 118, 507-517. doi: 10.1161/CIRCULATIONAHA. 108.778795

Oyamada, M., Oyamada, Y., Komatsu, K., Mori, M., and Takamatsu, T. (2000). In vitro cardiomyocytic differentiation of mouse embryonic stem cells deficient in gap junction protein connexin43. Card. Vasc. Regen. 1, 54-64.

Oyamada, M., Takebe, K., and Oyamada, Y. (2013). Regulation of connexin expression by transcription factors and epigenetic mechanisms. Biochim. Biophys. Acta 1828, 118-133. doi: 10.1016/j.bbamem.2011.12.031

Oyamada, Y., Komatsu, K., Kimura, H., Mori, M., and Oyamada, M. (1996). Differential regulation of gap junction protein (connexin) genes during cardiomyocytic differentiation of mouse embryonic stem cells in vitro. Exp. Cell Res. 229, 318-326. doi: 10.1006/ excr.1996.0377 
Parekkadan, B., Berdichevsky, Y., Irimia, D., Leeder, A., Yarmush, G., Toner, M., et al. (2008). Cell-cell interaction modulates neuroectodermal specification of embryonic stem cells. Neurosci. Lett. 438, 190-195. doi: 10.1016/j.neulet.2008.03.094

Pfannkuche, K., Liang, H., Hannes, T., Xi, J., Fatima, A., Nguemo, F., et al. (2009). Cardiac myocytes derived from murine reprogrammed fibroblasts: intact hormonal regulation, cardiac ion channel expression and development of contractility. Cell Physiol. Biochem. 24, 73-86. doi: 10.1159/000227815

Richards, M., Tan, S. P., Tan, J. H., Chan, W. K., and Bongso, A. (2004). The transcriptome profile of human embryonic stem cells as defined by SAGE. Stem Cells 22, 51-64. doi: 10.1634/stemcells.22-1-51

Robinton, D. A., and Daley, G. Q. (2012). The promise of induced pluripotent stem cells in research and therapy. Nature 481, 295-305. doi: 10.1038/nature10761

Sharovskaya, Y. Y. (2011). Intercellular interactions through gap junctions in embryonic stem cells. Biophysics 56, 86-89. doi: 10.1134/S0006350911010192

Sharovskaya, Y. Y., Lagarkova, M. A., Kiselev, S. L., and Chailakhyan, L. M. (2009). Gap junctional intercellular communication in human embryonic stem cells during spontaneous differentiation. Dokl. Biol. Sci. 427, 387-390.

Sharovskaya, Y. Y., Philonenko, E. S., Kiselev, S. L., and Lagarkova, M. A.
(2012). De novo reestablishment of gap junctional intercellular communications during reprogramming to pluripotency and differentiation. Stem Cells Dev. 21, 2623-2629. doi: $10.1089 / \mathrm{scd} .2011 .0707$

Takahashi, K., Tanabe, K., Ohnuki, M., Narita, M., Ichisaka, T., Tomoda, K., et al. (2007). Induction of pluripotent stem cells from adult human fibroblasts by defined factors. Cell 131, 861-872. doi: 10.1016/j.cell.2007.11.019

Takahashi, K., and Yamanaka, S. (2006). Induction of pluripotent stem cells from mouse embryonic and adult fibroblast cultures by defined factors. Cell 126, 663-676. doi: 10.1016/j.cell.2006.07.024

Thomson, J. A., Itskovitz-Eldor, J., Shapiro, S. S., Waknitz, M. A., Swiergiel, J. J., Marshall, V. S., et al. (1998). Embryonic stem cell lines derived from human blastocysts. Science 282, 1145-1147. doi: 10.1126/science.282.5391.1145

Todorova, M. G., Soria, B., and Quesada, I. (2008). Gap junctional intercellular communication is required to maintain embryonic stem cells in a non-differentiated and proliferative state. J. Cell. Physiol. 214, 354-362. doi: $10.1002 / j c p .21203$

Van Kempen, M., Van Ginneken, A., De Grijs, I., Mutsaers, N., Opthof, T., Jongsma, H., et al. (2003). Expression of the electrophysiological system during murine embryonic stem cell cardiac differentiation. Cell Physiol. Biochem. 13, 263-270. doi: 10.1159/000074541
Westfall, M. V., Pasyk, K. A., Yule, D. I., Samuelson, L. C., and Metzger, J. M. (1997). Ultrastructure and cell-cell coupling of cardiac myocytes differentiating in embryonic stem cell cultures. Cell Motil. Cytoskeleton 36 43-54.

Wolvetang, E. J., Pera, M. F., and Zuckerman, K. S. (2007). Gap junction mediated transport of shRNA between human embryonic stem cells. Biochem. Biophys. Res. Commun. 363, 610-615. doi: 10.1016/j.bbrc.2007.09.035

Wong, R. C. B., Dottori, M., Koh, K. L. L., Nguyen, L. T. V., Pera, M. F., and Pebay, A. (2006). Gap junctions modulate apoptosis and colony growth of human embryonic stem cells maintained in a serumfree system. Biochem. Biophys. Res. Commun. 344, 181-188. doi: 10.1016/j.bbrc.2006.03.127

Wong, R. C., Pebay, A., Nguyen, L. T., Koh, K. L., and Pera, M. F. (2004). Presence of functional gap junctions in human embryonic stem cells. Stem Cells 22, 883-889. doi: 10.1634/stemcells.22-6-883

Wong, R. C. B., Pera, M. F., and Pebay, A. (2008). Role of gap junctions in embryonic and somatic stem cells. Stem Cell Rev. 4, 283-292. doi: 10.1007/s12015-008-9038-9

Worsdorfer, P., Maxeiner, S. Markopoulos, C., Kirfel, G., Wulf, V., Auth, T., et al. (2008). Connexin expression and functional analysis of gap junctional communication in mouse embryonic stem cells. Stem Cells 26, 431-439. doi: 10.1634/stemcells.2007-0482
Yamamoto, M., Tase, N., Okuno, T., Kondo, Y., Akiba, S., Shimozawa, N., et al. (2007). Monitoring of gene expression in differentiation of embryoid bodies from cynomolgus monkey embryonic stem cells in the presence of bisphenol A. J. Toxicol. Sci. 32, 301-310. doi: 10.2131/jts.32.301

Conflict of Interest Statement: The authors declare that the research was conducted in the absence of any commercial or financial relationships that could be construed as a potential conflict of interest.

Received: 21 April 2013; accepted: 13 June 2013; published online: 03 July 2013.

Citation: Oyamada M, Takebe K, Endo A, Hara S and Oyamada Y (2013) Connexin expression and gap-junctional intercellular communication in ES cells and iPS cells. Front. Pharmacol. 4:85. doi: 10.3389/fphar.2013.00085

This article was submitted to Frontiers in Pharmacology of Ion Channels and Channelopathies, a specialty of Frontiers in Pharmacology.

Copyright (c) 2013 Oyamada, Takebe, Endo, Hara and Oyamada. This is an open-access article distributed under the terms of the Creative Commons Attribution License, which permits use, distribution and reproduction in other forums, provided the original authors and source are credited and subject to any copyright notices concerning any thirdparty graphics etc. 